\title{
Análise das funcionalidades do chá de Camellia sinensis
}

\author{
Analysis of Camellia sinensis tea functionalities \\ Análisis de las funcionalidades del té de Camellia sinensis
}

Recebido: 11/10/2021 | Revisado: 19/10/2021 | Aceito: 25/10/2021 | Publicado: 27/10/2021

\author{
Ana Paula Marques \\ ORCID: https://orcid.org/0000-0002-8970-1510 \\ Faculdade Integrada Carajás, Brasil \\ E-mail: anapaulamarques2804@gmail.com \\ Jânio Sousa Santos \\ ORCID: https://orcid.org/0000-0003-2180-1109 \\ Faculdade Integrada Carajás, Brasil \\ E-mail: santosjs.food@gmail.com
}

\begin{abstract}
Resumo
O chá verde produzido por meio da Camellia sinensis tornou-se um produto extremamente popular no Brasil na última década, frente a fama de contribuir com a perca de peso e gordura corporal. No entanto, o chá verde pode apresentar benefícios a saúde além perca de peso. Assim este estudo teve como objetivo geral expor as principais funcionalidades do (chá verde) C. sinensis, tanto in vitro como in vivo. Para atingir ao objetivo proposto foi realizada uma pesquisa bibliográfica exploratório, por meio de investigações em documentos científicos publicados na literatura disponível nas plataformas Scielo, Pubmed e repositório de universidades. Observou-se então que chá verde apresente funcionalidades frente a perca de peso, ação antioxidante, contribui na melhora de doenças cardíacas, cânceres, diabetes, ação antibacteriana, antiviral. Em relação as contraindicações, não foram identificadas, no entanto o excesso de chá verde pode causar irritação no estômago de algumas pessoas, ademais, a superdosagem com o chá seria praticamente impossível. Faz preciso o desenvolvimento de mais estudos a fim de identificar mais a fundo as funcionalidades do chá verde da $C$. sinensis para a população e pacientes em tratamentos específicos e comprovar de fato sua eficácia, garantindo mais segurança nas prescrições e indicações aos pacientes.
\end{abstract}

Palavras-chave: Antioxidante; Bioativos; Chás; Infusão.

\begin{abstract}
Green tea produced by Camellia sinensis has become an extremely popular product in Brazil in the last decade, due to the reputation of contributing to weight loss and body fat. However, green tea may have health benefits beyond weight loss. Thus, this study aimed to expose the main functionalities of (green tea) C. sinensis, both in vitro and in vivo. To achieve the proposed objective, an exploratory bibliographic research was carried out, through investigations in scientific documents published in the literature available on Scielo, Pubmed and university repository platforms. It was observed then that green tea presents functionalities against weight loss, antioxidant action, contributes to the improvement of heart disease, cancer, diabetes, antibacterial and antiviral action. Regarding contraindications, they were not identified, however the excess of green tea can cause irritation in the stomach of some people, moreover, overdosing with tea would be practically impossible. It is necessary to carry out more studies in order to further identify the functionalities of green tea from $C$. sinensis for the population and patients in specific treatments and in fact prove its effectiveness, ensuring more safety in prescriptions and indications to patients.
\end{abstract}

Keywords: Antioxidant; Bioactives; Teas; Infusion.

\section{Resumen}

El té verde producido por Camellia sinensis se ha convertido en un producto extremadamente popular en Brasil en la última década, debido a la reputación de contribuir a la pérdida de peso y la grasa corporal. Sin embargo, el té verde puede tener beneficios para la salud más allá de la pérdida de peso. Así, este estudio tuvo como objetivo exponer las principales funcionalidades de (té verde) C. sinensis, tanto in vitro como in vivo. Para lograr el objetivo propuesto, se realizó una investigación bibliográfica exploratoria, a través de investigaciones en documentos científicos publicados en la literatura disponible en Scielo, Pubmed y plataformas de repositorio universitario. Se observó entonces que el té verde presenta funcionalidades contra la pérdida de peso, acción antioxidante, contribuye a la mejora de enfermedades cardíacas, cáncer, diabetes, acción antibacteriana y antiviral. En cuanto a las contraindicaciones, no se identificaron, sin embargo el exceso de té verde puede causar irritación en el estómago de algunas personas, además, la sobredosis con té sería prácticamente imposible. Es necesario realizar más estudios con el fin de seguir identificando las funcionalidades del té verde de $C$. sinensis para la población y los pacientes en tratamientos específicos y de hecho demostrar su eficacia, garantizando una mayor seguridad en las prescripciones e indicaciones a los pacientes.

Palabras clave: Antioxidante; Bioactivos; Tés; Infusión. 


\section{Introdução}

A Camellia sinensis é uma planta tática para a saúde humana no século XXI. Por tratar-se de uma bebida abundantemente disponível e de baixo custo, torna-se viável o seu uso como um importante auxiliar no manejo nutricional em diversas patologias (Senger, Schwanke \& Gottlieb, 2010). Os mesmos autores afirmam, que não se pode esperar que um único alimento tenha a capacidade de conceder um impacto de grandes proporções sobre a saúde pública. Embora seja importante observar que mesmo um efeito modesto, pode ter um impacto importante sobre as causas mais predominante de morbidade e mortalidade das Doenças Crônicas Não Transmissíveis merecendo assim maior atenção, tendo em visão que em pouco tempo o consumo cotidiano de chá verde poderá ser bem-visto como parte das dietas ocidentais.

Lamarão e Fialho (2009) defendem que o papel do chá verde contribui para a diminuição do peso corpóreo, vem destacando também uma série de benefícios à saúde está bebida.

Em um resultado de pesquisa comprovado por Duarte, Pretto, Nörnberg e Conter (2014) do suplemento Chá verde ( $C$. sinensis) e Modo Jump Fit de 500 mg, se mostra eficaz, por ter uma ação positiva em relação à redução do índice de gordura corporal, principalmente sobre perda de peso e redução de cerco abdômen, pois esses parâmetros para melhorar a saúde e qualidade de vida. Ao mesmo tempo, também enfatizou pesquisa para provar a eficácia beba chá verde para perder peso, reduza as medidas e melhore a saúde, e cada vez mais procurando suplementos ou fórmulas que atuam sobre este problema. Graças a está pesquisa, outras instruções reforçadas suplemento de chá verde.

Em pesquisa, Lamarão e Fialho (2009) demostraram 4\% de aumento em relação a energia gasta em um dia (20 h) que e uma significante diminuição no quociente respiratório de 0,88 para apenas 0,85 , durante as 24 h. Não ocorreu alteração na concentração de nitrogênio urinário e a excreção urinária de norepinefrina durante 24 h foi maior durante o tratamento com o chá verde do que com os placebos.

A literatura continua a provar o papel potencial do chá verde na regulação dos processos anti-inflamatórios, antitumorais, antiaterosclerose, redução do açúcar no sangue e controle de peso (Senger; Schwanke \& Gottlieb, 2010).

Devido à atividade biológica as plantas estão diretamente relacionadas à qualidade e a quantidade de substâncias biologicamente ativas presentes no material vegetais, falta de observação padronizada métodos de preparação e quantificação tornam isso difícil em comparação de resultados de pesquisa utilizável (Firmino \& Miranda, 2015). Desta forma, o objetivo do presente estudo foi expor as principais funcionalidades do (chá verde) C. sinensis, tanto in vitro como in vivo.

\section{Metodologia}

A fim de atingir ao objetivo proposto, esta pesquisa se caracteriza como bibliográfica exploratória, por meio de análises em documentos científicos publicados nas plataformas Scielo, PubMed e repositório de universidades. As palavraschave empregadas na busca foram: chás; chá verde; $C$. sinensis; emagrecimento; bioativos; antioxidante; infusão. Os critérios de inclusão utilizados para definir quais estudos eram pertinentes a serem discutidos foram: Estudos que analisaram a eficiência do chá verde; Estudos que apresentaram definições do chá verde; estudos que apresentaram os principais grupos de polifenóis. Assim, os estudos foram analisados e desenvolveu-se uma discussão coerente e lógica quanto a temática proposta.

\section{Resultados e Discussão}

\section{Chás}

O chá, no Brasil é relacionada a infusões feitas a base de ervas, plantas. Por definição oficial chá é um produto composto por vegetais; fermentado ou não, fragmentado/moído ou não; tostado ou não. Deve ser regulamentado por meio do Regulamento Técnico de Espécies Vegetais para o Preparo de Chás. Ademais pode ser acrescido de especiarias e aromas a fim 
de conferir-lhe mais sabor. A mesma resolução define que esse produto deve ser chamado de chá, seguido do nome comum da espécie vegetal empregada, podendo ser submetido a processos de obtenção e/ou características específicas (Brasil, 2005).

Salienta-se que todo chá é uma infusão, no entanto, nem toda infusão se classifica como chá. Quimicamente, infusão é uma bebida que resulta da imersão de ingredientes em água quente. No mercado dos chás, considera-se que o chá resulta da mistura da planta $C$. sinensis a água quente, a mistura de água quente com demais plantas chama-se apenas infusão (Appelt, 2019). No entanto, Carmo e Silvestre (2012) ressaltam ser um equívoco considerar que o chá é somente a planta $C$. sinensis usada por japoneses e ingleses, considerando as demais plantas apenas como infusão.

Conforme Oliveira (2016) os chás fazem parte de diversas culturas mundiais, desconsiderando a água in natura como uma bebida o chá é a segunda mais consumida mundialmente, e o hábito de bebê-lo se deu frente as suas propriedades medicinais, já que possuem consideráveis compostos biologicamente ativos: vitaminas, sais minerais, alcalóides e polifenóis; que contribuem na diminuição do risco do desenvolvimento de diversas doenças e comorbidades (Oliveira, 2016).

Pazinato, Braibante, Braibante, Trevisan e Silva (2012) destacam que o homem, desde os tempos mais primórdios, faz uso de ervas e plantas na busca pela cura de enfermidades, por meio da ingestão de infusões dessas plantas, sendo esse o método mais remoto para tratamento e cura dessas enfermidades. Para esse fim, muitas plantas começaram a ser aplicadas em forma infusa e diversos benefícios para a saúde foram notados (Santos, 2019).

Senna (2013) destaca que a origem dos chás é rodeada por histórias e lendas. Historicamente, a China é considerada o país que deu origem aos chás por volta de 2737 - 2697 a.C., conforme relatos lendários o imperador Shen Nung que tinha o hábito de ferver sua água por questões de higiene, em uma de suas viagens parou para descansar na sombra de uma árvore, eventualmente algumas folhas caíram dentro da jarra que continha água fervida. Shen Nung se encantou pelo aroma e cor, além disso, após consumi-lo sentiu-se reconfortado e com um enorme bem-estar. No entanto, não existem relatos comprovatórios dessa história, porém sabe-se que os chineses produzem e consomem o chá desde a antiguidade.

Assim, o imperador Shen Nung incentivou a agricultura chinesa com destaque para o chá. Séculos mais tarde, o chá era uma decocção, as folhas passaram a ser fervidas com casca de laranja e leite. No mesmo período o chá converte-se em uma infusão, a qual as folhas passavam por processo de secagem e posteriormente eram moídas, assim no momento do consumo acrescentava-se as folhas moídas a água fervente e agita-se com uma varinha de bambu (Senna, 2013).

O chá foi levado para o Japão durante o século IX, onde durante muito tempo, foi uma bebida tão valiosa que era consumido apenas pelo imperador. A partir do século XIII por meio das viagens de Marco Polo o chá se disseminou pela Ásia. A partir de 1500 foi levado a Europa por meio das expedições de Vasco da Gama, porém só teve seu consumo disseminado um século mais tarde, em 1601 com a criação da Companhia Holandesa das Índias Orientais responsável pela difusão massiva e mundial do chá, o primeiro carregamento de chá de proporções consideráveis foi enviado a Europa em 1606 e, em pouco tempo se tornou moda no continente. Em 1650 foi enviado a América do Norte. Em 1658 o chá ganha popularidade na mídia, aparecendo em um anúncio publicitário em um diário de Londres chamado Mercurios Political (Oliveira, 2016).

Em 1662 o chá foi introduzido a corte britânica por Catarina de Bragança. Como pagamento de dote matrimonial, assim o hábito da rainha de consumir chá em todas as horas foi replicado por boa parte da corte inglesa. Anos mais tarde, em 1820, a Duquesa Ana de Bedford deu início a tradição inglesa de consumir uma xícara de chá diariamente as cinco da tarde em ponto. Suas amizades consideraram uma prática agradável e passaram a manter o costume (Oliveira, 2016).

Conforme Carmo e Silvestre (2012) o chá chegou ao Brasil por meio de um agricultor português chamado Luiz de Abreu. Ele presenteou Dom João VI com sementes de C. sinensis, quando chegou ao país. As primeiras plantações das sementes foram feitas em 1808 no Jardim Botânico do Rio de Janeiro.

Contemporaneamente o chá é uma bebida disseminada em todo o mundo, de acordo com o relatório da International Institute for Sustainable Development - IISD (2019) correspondente ao ano de 2017, três bilhões de xícaras de chá são 
consumidas por dia em todo o mundo. Dados apresentados pela Food and Agriculture Organization (FAO) publicadas pela IISD (2019) preveem que, até 2024, o setor de chá cresça a uma taxa anual de cerca de 4 a 5,5\% e alcance 73 bilhões de dólares.

No cenário brasileiro o consumo de chá ainda se mantém abaixo da média mundial, pois no Brasil as pessoas ainda preferem o cafezinho. Conforme dados do SEBRAE (2021) o brasileiro consome em média dez xícaras da bebida por ano, no entanto estima-se que até 2023 o setor tenha um crescimento de 43\%, levando em consideração os novos hábitos saudáveis da população.

Esteves (2021) destaca que um relatório publicado pela Euromonitor mostrou que o consumo de chá no Brasil cresceu 25\% entre 2013 e 2018, correspondendo a uma média quase que duas vezes maior que o índice mundial. No ano de 2019 o segmento movimentou R $\$ 2,2$ bilhões no Brasil. O setor emprega no país mais de 450 mil colaboradores, conforme dados do SEBRAE (2021).

No que tange as importações e exportações, no ano de 2018 o Brasil exportou 84,2\% da produção nacional para os EUA; $10,4 \%$ para o Japão e; $1,2 \%$ para Moçambique. Quanto as importações, o Brasil importou da China (31,5\%); dos EUA $(10,4 \%)$ e da Espanha (10\%) (SEBRAE, 2021).

Carmo e Silvestre (2012) destaca que o hábito de consumir chá no Brasil está deixando de ser algo associado a cura de doenças para um hábito relacionado ao prazer e bem-estar por meio de experiências sensoriais, como ocorre em outros países.

\section{Chás de Camellia sinensis}

A C. sinensis é uma planta originária da Ásia, pertencente à família Theaceae do gênero Camellia e espécie sinensis (Blanco, 2020). É uma planta do tipo arbustivo de porte pequeno, alternadas e inteiras, suas margens são serreadas e sua textura coriácea (Duarte \& Menarim, 2006). Blanco (2020) destaca ainda que possui flores brancas, pequenas, com quatro ou cinco pétalas, e aparecem em grupos de até quatro.

Santos (2012) conta que, historicamente o cultivo da C. sinensis se deu por monges budistas no Himalaia, que faziam uso das folhas para preparar uma bebida tradicional. Uma lenda chinesa do ano 2737 a.C. apresentava os efeitos terapêuticos do chá verde produzido com a $C$. sinensis, sendo esse o primeiro relato histórico que associa o consumo da bebida com os efeitos benéficos à saúde. Conforme Senger, Schwanke e Gottlieb (2010) por meio das folhas da planta C. sinensis produz-se o chá.

Reto, Figueira, Filipe e Almeida (2008) ressalta que a C. sinensis possui uma composição química complexa que a confere uma variedade de sabores e aromas dependendo das condições de cultivo, coleta, preparo e acondicionamento das folhas.

Duboc (2015) afirma que por meio da planta C. sinensis é possível produzir cinco tipos diferentes de chás: branco, preto, verde, amarelo, oolong e vermelho, o esquema apresentado na Figura 1 relata o processo de beneficiamento para obtenção desses tipos de chás. No entanto, Lopes (2015) reconhece a existência de oito tipos básicos de chás provenientes da planta, sendo diferenciados apenas pelo processo de beneficiamento das folhas, são estes: chá branco, chá verde, chá amarelo, chá vermelho, chá preto, oolong, matcha e banchá.

O chá branco passa por menos processamento, contendo apenas folhas jovens e brotos da planta assim os brotos passam por cozimento no vapor e são secos em sequência à colheita a fim de evitar oxidação, com isso resulta no mais sutil de todos os tipos de chás. Assim, são mais raros e possuem custo mais elevado (Gondoin, Grussu, Stewart \& Mcdougal 2010; Carmo \& Silvestre, 2012). O chá verde passa por um processo de eliminação das enzimas de oxidação imediatamente após a colheita das folhas a fim de preservar as características e não é submetido a fermentação, depois é fragmentado e seco (Duboc, 2015). 
O chá preto é o tipo mais submetido a processamento. As folhas são oxidadas por completo, atingindo cor preta antes mesmo do processo de secagem. Isso garante ao chá mais adstringência e complexidade ao seu sabor e menos conotações vegetais, que são encontradas em outros chás (Carmo \& Silvestre, 2012).

O chá Oolong é submetido a oxidação parcial, ficando entre a oxidação aplicada nos chás preto e verde. Possui um tom escuro, se assemelhando ao chá preto, porém o sabor se aproxima mais ao do chá verde, levemente menos amargo (Carmo $\&$ Silvestre, 2012).

Duboc (2015) destaca que os que os efeitos benéficos dos chás se relacionam ao teor de polifenóis. Os polifenóis são os componentes biologicamente ativos, que apresentam propriedades funcionais e que estão relacionados com a qualidade sensorial de alimentos de origem vegetal (coloração, amargor e adstringência). Como definido pelo International Food Information Council em 2008, alimentos funcionais são aqueles que provêm benefícios adicionais à saúde aos já atribuídos nutrientes que contêm (Lamarão \& Fialho, 2009).

Duboc (2015) complementa que o teor de polifenóis, que correspondem a cerca de $30 \%$ do peso seco das folhas, sendo os flavonóides os mais abundantes, principalmente a galato-3-epigalocatequina (EGCG) (Tabela 1).

A composição fitoquímica das folhas da C. sinensis depende de vários fatores como clima, práticas de cultivo, estação do ano, variedade e idade da planta. Duarte e Menarim (2006) descobriram que ela possui em sua composição química diferentes grupos de compostos constituídos principalmente de polifenóis. Segundo Freitas \& Navarro (2007) suas folhas sobressaem aos aspectos de teobrominas e teaflavinas além de hídricos, proteicos, glicídicos, cafeínas, sais minerais, vitaminas, e derivados polifenólicos. Também apresenta uma elevada quantidade de flavonoides como as catequinas por exemplo (Urzedo, 2020). 
Research, Society and Development, v. 10, n. 14, e110101421638, 2021

(CC BY 4.0) | ISSN 2525-3409 | DOI: http://dx.doi.org/10.33448/rsd-v10i14.21638

Figura 1 - Processo de obtenção dos diferentes tipos de chás de $C$. sinensis.

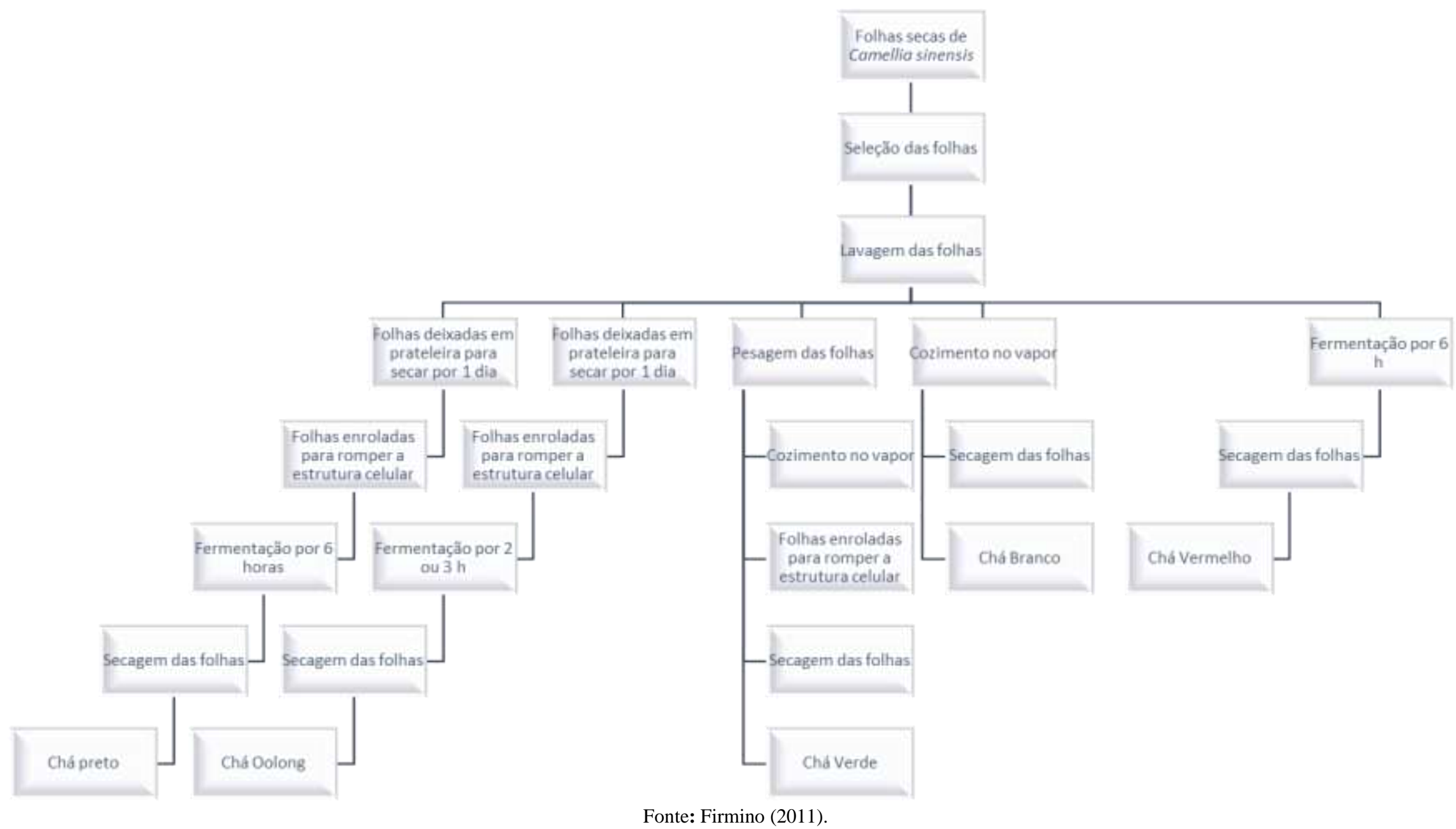


Tabela 1 - Composição do chá verde, preto e da infusão de chá preto.

\begin{tabular}{|c|c|c|c|}
\hline Componentes (\%) & Chá Verde ${ }^{1}$ & Chá Preto $^{1}$ & Infusão de Chá Preto $^{2}$ \\
\hline Proteínas & 15 & 15 & Traço \\
\hline Aminoácidos & 4 & 4 & 3,5 \\
\hline Fibras & 26 & 26 & 0 \\
\hline Outros carboidratos & 7 & 7 & 4 \\
\hline Lipídios & 7 & 7 & Traço \\
\hline Pigmentos & 2 & 2 & Traço \\
\hline Minerais & 4 & 4 & 4,5 \\
\hline Compostos fenólicos ${ }^{3}$ & 30 & 5 & 4,5 \\
\hline Compostos fenólicos oxidados ${ }^{4}$ & 0 & 25 & 4,5 \\
\hline
\end{tabular}

Nota: ${ }^{1}$ Dados referentes ao peso seco das folhas; ${ }^{2}$ Tempo de infusão das folhas: 3 min; ${ }^{3}$ Principalmente flavonoides; ${ }^{4}$ Principalmente tearubiginas e teoflavinas

Fonte: DUBOC (2015).

A ANVISA alega que propriedades funcionais são aquelas relativas ao papel metabólico ou fisiológico que o nutriente ou não nutriente tem no crescimento, desenvolvimento, manutenção e outras funções normais do organismo humano (Brasil, 1999). Os principais grupos de polifenóis estão apresentados na Tabela 2, com um exemplo e seu respectivo alimento de origem.

Tabela 2 - Principais grupos de polifenóis, exemplos de substâncias presentes no grupo e alimento fonte dessa substância

\begin{tabular}{c|c|c}
\hline Grupo de Polifenol & Exemplo & Alimento \\
\hline Ácido fenólicos & Ácido clorogênico & Uva \\
\hline Estilibenos & Resveratrol & Aipo \\
\hline Cumarina & Furanocumarinas & Linhaça \\
\hline Ligninas & Lignanas & Chá \\
\hline Flavonóides & Catequinas & . \\
\hline
\end{tabular}

Fonte: Faller e Failho (2009).

Faller e Fialho (2009) complementam que o grupo dos flavonóides possui mais de 5 mil compostos identificados, sendo o maior e mais estudado. Os polifenóis apresentam ações fisiológicas relacionadas à prevenção de doenças cardiovasculares, neurodegenerativas e câncer, principalmente em função da elevada capacidade antioxidante (Faller \& Fialho, 2009; Hilal \& Engelhardt, 2007). O aumento do consumo dos diversos tipos de chás, mas principalmente do chá verde, está relacionado aos efeitos benéficos que a bebida pode trazer para a saúde, sendo associado à redução do colesterol sérico, redução dos riscos de doenças cardiovasculares e câncer, propriedades antialérgicas, antiesclerótica e antibacteriana, além de possuírem minerais e vitamina K (Lima, Mazzafera, Moraes, \& Silva, 2009).

Entretanto, a propriedade que mais favoreceu o aumento do consumo de chá verde é a relação dele com emagrecimento. Diversas dietas para perda de peso a base do chá verde são veiculadas nos meios de comunicação populares, como internet e revistas, indicando até 5 xícaras da bebida por dia. Contudo, a American Dietetic Association sugere o consumo de 4 a 6 xícaras de chá verde ao dia, a fim de se obter os efeitos benéficos da bebida à saúde (Lamarão \& Fialho, 2009). 
Alguns estudos relacionam a indução da perda de peso com o efeito termogênico e com a oxidação lipídica, o que promove o gasto energético, resultante da interação entre as catequinas e a cafeína presentes no chá verde (Freitas \& Navarro, 2007), resultando na redução da gordura corporal e nos índices de colesterol séricos.

\section{Funcionalidades atreladas ao chá verde}

O chá verde é estudado a quase três décadas, conforme estudos publicados na literatura, de acordo com Manfredini, Martins \& Benfato (2004) os resultados encontrados nesses estudos têm sido importantes para afastar mitos e evidenciar alguns benefícios do chá verde para a saúde, em relação ao seu consumo regular. Assim, tornou-se um alimento funcional que, quando consumido em associação a alimentação cotidiana pode proporcionar benefícios fisiológicos e específicos, frente aos seus componentes ativos. Saigg (2009) complementa que o consumo do chá verde vem sendo associado a uma variedade de ações potencialmente benéficas à saúde, como alternativa para prevenir e minimizar os efeitos de inúmeras enfermidades, como doenças cardiovasculares e até mesmo o câncer.

\section{Ação antioxidante}

Santos et al. (2020) analisaram um chá misto otimizada e identificaram um alto teor de compostos fenólicos totais, assim como atividade antioxidante e antiproliferativa in vitro. Já Manfredini, Martins e Benfato (2004) explicam que os polifenólicos existentes na composição do chá verde, como as catequinas (Figura 2), epicatequinas, galocatequinas, epigalocatequinas e epicatequinas galato são flavonóides contribuem com essas funcionalidades.

Figura 2 - Catequinas do chá verde.

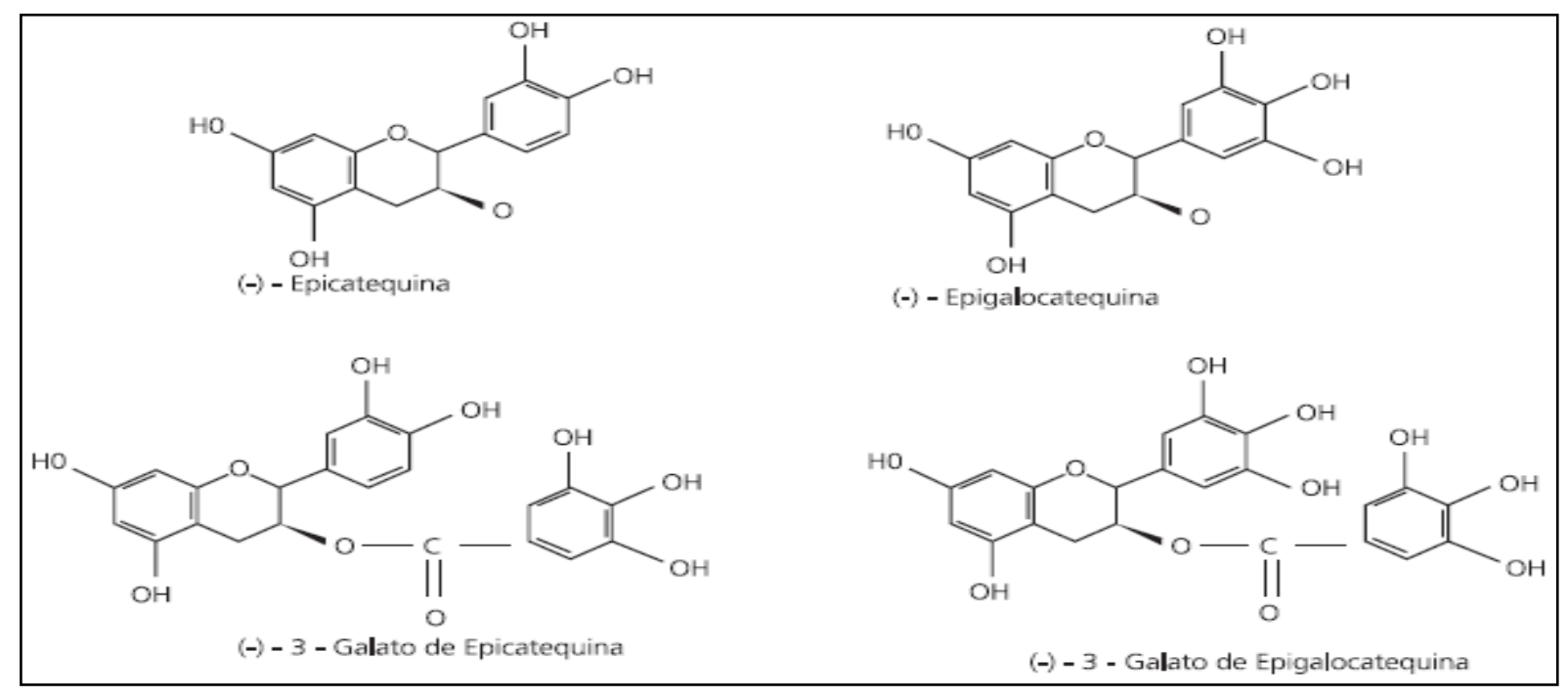

Fonte: Lamarão e Fialho (2009).

Durante o processamento as folhas do chá verde são expostas ao vapor de água e colhidas em seguida, secando naturalmente. Por meio dessa técnica é possível preservar os "polifenóis naturais que variam muna proporção de 45 a 90\% em relação às propriedades biológicas" (Sabu, Smitha \& Kuttan, 2002). Dentre as atividades promovidas pelo chá verde, destacase sua ação antioxidante, Miranda (2013) afirma que essa é considerada uma das principais propriedades farmacológicas do chá verde. Nishiyama et al. (2010) contataram que o efeito antioxidante foi identificado em percentuais de eficiência do sequestro dos radicais livres. 
Conforme Cabrera, Gimenez e Lopez (2003) em um estudo que avaliou 45 amostras de diferentes chás, a fim de dosar os componentes com efeito antioxidante, sendo esses Cromo (Cr), Manganês (Mn), Selênio (Se), Zinco (Zn) e catequinas, assim comprovou-se que o chá verde foi o que apresentou maiores concentrações de catequinas, em especial o galato de epigalocatequina (EGCG) e o epigalocatequina (ECG). Ademais, Rijken et al. (1996) constataram que o consumo de um litro de chá verde diariamente, minimiza a concentração de dialdeído malônico e 8-hidroxideoxiguanosina urinária, com apenas uma semana de ingestão do chá, além disso a suplementação de catequinas do chá verde diminuiu consideravelmente os índices plasmáticos do hidroperóxido de fosfatidilcolina em um período de 60 min após o consumo.

Manfredini, Martins e Benfato (2004,) afirmam que "estudos in vitro realizados em animais, sobre a oxidação lipídica, revelaram que certas catequinas são cerca de dez vezes mais eficazes, como antioxidantes, do que a vitamina E”.

Cooper, Morré e Morré (2005) constaram ainda que o chá verde é rico em flavonóides bioativos com grande ação antioxidante. Dentre os benefícios das terapias antioxidantes destaca-se o enfraquecimento dos efeitos nocivos dos radicais livres. A EGCG projete ainda quanto aos efeitos oxidativo e envelhecimento, atenuando os índices de peróxido de hidrogênio e protegendo contra os efeitos naturais da idade (Rietveld \& Wiseman, 2003).

Nishiyama et al. (2010) avaliaram o efeito do tempo, modo de acondicionamento e preparo do chá verde a fim de avaliar os compostos fenólicos e atividade antioxidante do chá verde brasileiro. Após ensaios os autores constaram que o chá verde deve ser preparado com tempo de infusão mínimo de $5 \mathrm{~min}$, sob agitação leve e a granel a fim de garantir suas propriedades antioxidantes. Conforme os mesmos autores, o chá em sachê reduz a extração dos compostos bioativos. Quanto ao armazenamento, os autores identificaram que as propriedades se mantiveram tanto em armazenamento em geladeira quanto em temperatura ambiente, sem aparentes alterações em seus principais bioativos e sem perdas das suas propriedades antioxidantes

\section{Ação contra doenças crônicas}

Miranda (2013) destaca que a ingestão diária de chá verde apresentou efeitos preventivos em relação às doenças crônicas resultantes de fatores nutricionais e pelo consumo de cigarro. Conforme Palermo, Hernando, Dertinger, Kende \& Gasiewicz (2003) pesquisas realizadas pelo National institute of environmental Health Sciences, da Universidade de Rochester, Nova Iorque mostraram que o EGCG e a EGC na composição do chá verde mitigam a ação dos receptores arilhidrocarboneto, sendo esse um fator de transcrição ligante-dependente que pode ser ativado por numerosos compostos naturais ou sintéticos de estrutura química variada, tais como hidrocarbonetos aromáticos policíclicos, indóis e flavonoides. Assim, tem função relevante no processo de ativação de genes que podem causar câncer em células humanas.

Faria, Santos e Viana (2006) analisaram efeitos do chá verde em população de origem japonesa e identificaram que a associação do chá verde com outros elementos da dieta japonesa, pode influenciar na minimização dos riscos de ocorrências de câncer e doenças do coração, relacionado com a longevidade dessa população.

Senger, Schwanke e Gottlieb (2010) complementam que: o chá verde participa na prevenção de neoplasias malignas pela ação de suas catequinas, com possíveis efeitos protetores do dano causado pelos RL no DNA das células e também na indução de apoptose nas células tumorais. As catequinas do chá verde podem reduzir a proliferação de células de câncer de mama in vitro e diminuir o crescimento de tumor de mama em roedores. Além disso, os estudos in vitro demonstraram que a combinação de EGCG e tamoxifeno é sinergicamente citotóxica para células cancerosas. Estes resultados sugerem que as catequinas têm potencial significativo no tratamento do câncer da mama.

Anneli, Pereira, De Oliveira, Bernardo, Grigoleto (2016) afirmam que o chá verde possui potencial anticarcinogênico melhorando diariamente a qualidade no tratamento de pacientes com câncer, visto aos efeitos da catequina, que age na minimização de proliferação das células cancerígenas com seus efeitos inibidores da agressão dos radicais ao DNA. 
Miranda (2013) destaca que o chá verde possui ainda atividade antidiabética. Anderson e Polansky (2002) avaliaram, por meio de ensaio epididimal de células adiposas, que o chá ingerido normalmente, ou seja, consumo de sache de $2 \mathrm{~g}$ infuso em $237 \mathrm{~mL}$ de água quente por 5 min, maximizou a ação da insulina, sendo que a maior atividade se atribuiu ao EGCG, seguido por ECG, teoflavinas e taninos. Ademais, os mesmos autores constaram que uma mistura de catequinas de chá verde se apresentou eficiente na extinção do aumento do índice de glicose e de insulina plasmática em animais, logo após consumo de carboidratos. As catequinas presentes no chá foram capazes de inibir enzimas que hidrolisam carboidratos, principalmente a $\alpha$-amilase.

Komorita et al. (2020) identificaram que o hábito de consumir chá verde relaciona-se a um risco menor de mortalidade entre pacientes com diabetes do tipo 2, que possuem maior chances de sofrer com enfermidades circulatórias, demência, câncer e fraturas ósseas. Faria (2015) demostrou que o chá verde atua como coadjuvante na prevenção e no tratamento de pacientes com complicações renais ou de retina causadas por diabetes.

Senger, Schwanke e Gottlieb (2010,) destacam que, entre os vários efeitos biológicos do chá verde, observou-se seu efeito inibitório na expressão do gene fator de necrose tumoral alfa (TNF -alfa) mediado por meio de inibição da ativação de fator de transcrição kappa $\beta$ (NF -kappa $\beta$ ) e ativador proteico 1 (AP-1). O TNF-alfa costuma ser um mediador central em doenças inflamatórias crônicas, tais como artrite reumatóide e esclerose múltipla. Para testar a hipótese de que o chá verde poderia ser um agente preventivo para doenças inflamatórias crônicas, foram utilizados ratos transgênicos para o TNF -alfa, com a expressão do mesmo apenas nos pulmões. $\mathrm{O}$ rato transgênico TNF -alfa é um modelo animal da fibrose pulmonar idiopática humana e que desenvolve também, frequentemente, o câncer de pulmão. Após tratamento com chá verde na água potável durante quatro meses, descobriu-se que expressões de TNF -alfa e interleucina-6 (IL-6) foram inibidas nos pulmões desses ratos, sugerindo que o chá verde possa ter efeitos preventivos sobre doenças inflamatórias crônicas.

Block et al. (1992) afirmam que outra característica do consumo de chá verde está na diminuição do desenvolvimento de doenças coronárias. As concentrações de antioxidantes naturais conferem o segundo principal benefício dessa bebida, que á a minimização das chances de desenvolvimento de doenças coronarianas. A oxidação das lipoproteínas de baixa densidade é um dos motivos principais para o desenvolvimento desse tipo de enfermidade.

\section{Ação anti sobrepeso e obesidade}

Para Senger, Schwanke e Gottlieb (2010) apesar de ainda existirem dados controversos, a maioria dos estudos se mostram satisfatórios, comprovando que o chá verde pode garantir benefícios ao tratamento de inúmeras enfermidades e patologias, principalmente no tratamento de obesidade e sobrepeso.

Pesquisas realizadas em humanos e in vitro têm apresentado resultados positivos quanto os componentes do chá são associados ao consumo da cafeína, contribuindo no gasto energético. Além de contribuir na perca de peso, o uso do chá verde contribui na diminuição do índice de colesterol total e de triacilglicerol bem como na prevenção da obesidade e das doenças relacionadas (Cardoso, 2011).

Hughes et al. (2008) identificaram que o consumo de flavonoides, contribui na manutenção do peso no decorrer do tempo, pois o grupo de pacientes que consumiu catequinas teve um aumento de peso e de IMC inferior ao grupo que não consumiu catequinas.

Manenti (2010) afirma que diversos estudos têm comprovado de tanto animais quanto humanos são beneficiados com o consumo de chá, essas pesquisas constataram minimização no consumo alimentar, maior utilização de lipídeos como fonte de energia e perca de peso corporal além de circunferência do quadril e relação cintura-quadril em humanos, avaliando-se, assim, o percentual de gordura e sua distribuição no corpo. 
De acordo com Beltran, Silva, Grignoli, Simionato, e Grignoli (2014) os flavonoides contidos no chá verde agem no sistema nervoso simpático respectivamente na modulação da noradrenalina, aumentando a termogênese e a oxidação lipídica, inibindo hipertrofia e hiperplasia dos adipócitos, precavendo que ocorram depósitos de gordura e ajustando o peso corporal. Os estudos demonstram que as catequinas exercem função essencial no controle do tecido adiposo e redução do apetite, sobretudo na regulação em que a EGCG compreende sobre enzimas do anabolismo e catabolismo lipídico, responsável pela determinação da sensação de saciedade. A dosagem recomendada para que os efeitos apareçam é em torno de 3 copos por dia, aproximadamente 240 a $320 \mathrm{mg}$ de polifenóis.

De acordo com Nagão, Komine, Soga, Meguro, Hase, Tanaka e Tokimitsu (2005) o consumo da bebida contendo altos teores de catequinas impede a peroxidação lipídica e garante alterações na concentração de LDL modificada por malondialdeído (LDL-MDA), sendo benéfica a patologia cardiovascular aterosclerótica. Ademais, o consumo de catequinas contribui para minimização da gordura corporal, além de contribuir na prevenção de enfermidades associadas ao estilo de vida, com destaque para a obesidade.

Ota, Soga, Shimotoyodome, Haramizu, Inaba, Murase (2005) avaliaram os efeitos do combinado de catequinas e do exercício físico praticado regularmente na energia despendida em humanos. Assim, os autores identificaram que o gasto energético nos pacientes aumentou, independente da prática de exercícios, desde que fosse associado ao consumo de catequinas, do que apenas pela atividade física isoladamente. Conforme os pesquisadores quando se associa o consumo de catequinas aos exercícios físicos regulares, aumenta-se o uso da própria gordura corporal como fonte de energia, frente ao estímulo do metabolismo lipídico no fígado ou no músculo esquelético, locais no qual as oxidações dos ácidos graxos livres aumentam.

Vilela e Souza (2015) relatam que estudos realizaram acompanham indivíduos que consumiram chá verde durante um período de três meses e contataram perca de peso variando entre 0,6 e $1,6 \mathrm{~kg}$, uma alteração de IMC de $0,2 \mathrm{a}-0,5 \mathrm{~kg} / \mathrm{m}^{2} \mathrm{e}$ redução na circunferência abdominal variando entre 0,3 a $-1,7$ cm e concluíram que a ingestão de chá verde influencia na perca de peso entre os pacientes pesquisados.

Para Vilela e Souza (2015) a C. sinensis contribui para prevenção da obesidade principalmente por sua composição de catequinas e cafeína. Estes compostos atuam estimulando o sistema nervoso simpático ativando seu efeito termogênico. Além desse, outros benefícios também estão presentes na utilização do chá verde como sua ação antioxidante, controle de patologia como diabetes e dislipidemias, além de doenças cardiovasculares, e ateroscleróticas.

\section{Ação antibactericida e antiviral}

Hamilton-Miller (1995) constataram que o extrato do chá verde se mostrou bacteriostático ou bactericida frente às bactérias Staphyloccus aureus, Staphylococcus epidermidis, Salmonella typhi, Salmonella typhimurium, Salmonella enteritidis, Shigella flexneri, Shigella dysenteriae e Vibrio spp, além de S.aureus oxacilina resistente.

Miranda (2013) afirma que o uso do chá verde pode ainda ser benéfico na prevenção contra as cáries, frente ao efeito bactericida sobre Streptococcus mutans e S.sobrinus .

Tanto Kawai et al. (2003) quanto Nance e Shearer (2003) relatam que o EGCG evita que as proteínas do HIV se associem às moléculas CD4 das células T-helper que se trata da primeira etapa de infecção pelo HIV. Conforme os autores, com base em modelos moleculares de EGCG, pode-se inspirar-se para criar novos medicamentos para o tratamento da SIDA.

\section{Contraindicações}

Conforme Santos e Silva (2017) a maioria dos estudos analisados que mostraram relação positiva entre chá verde e densidade mineral óssea foi em animais, seguida dos observacionais. Todos os estudos em animais mostraram associação 
positiva, no entanto, não é possível assegurar que esses mesmos resultados benéficos seriam encontrados em humanos, pois são organismos diferentes e possuem especificidades diversas. Os estudos observacionais indicam possível associação, que só pode ser confirmada também após os estudos clínicos controlados. Entre os estudos clínicos selecionados nesta revisão, nenhum apresentou efeito significante do chá verde sobre a densidade mineral óssea. Isso impossibilita a afirmação de que a suplementação de chá verde, ou de seus compostos é benéfica para prevenção e/ou tratamento de doenças como osteopenia e osteoporose, sendo necessária a realização de mais estudos que avaliem a ação desse composto em diferentes doses e tempo de suplementação.

Conforme Miranda (2013) apesar dos efeitos benéficos, o chá verde já foi considerado tóxico, além de apresentar efeitos adversos e possíveis problemas relacionados a superdosagem.

De acordo com Schmitz, Saito, Estevão e Saridakis (2005) França e Espanha já suspenderam a venda do extrato hidroalcoólico de chá verde, visto a suspeita de hepatoxicidade do mesmo, que incentivou a realização de diversos estudos a fim de comprovar tal suspeita, assim constataram a toxidade do extrato de chá verde e seus constituintes em culturas de hepatócitos de ratos, comprovando que o mesmo apresenta baixa toxicidade in vitro.

Em pessoas com estômago hipersensível, visto à presença do ácido clorogênio e aos taninos, a ingestão de chá verde pode desencadear em efeitos indesejáveis. O consumo intenso do chá pode resultar em hiperacidose, irritação gástrica, redução de apetite, além de constipação ou diarreia. No entanto, esses efeitos podem ser minimizados com a associação de leite ao chá verde (Hara, 1995).

Ademais, o consumo em excesso do chá verde, superdosagens superiores a cinco xícaras, pode provocar inquietação, aumento da excitabilidade reflexa e tremor, correspondendo aos primeiros efeitos de toxidade: vômito e espasmo abdominal, no entanto não é possível atingir uma dose fatal somente com o consumo do chá (Schmitz, Saito, Estevão \& Saridakis, 2005).

Duboc (2015) analisou a concentração de metais nas folhas e na infusão e pesquisar a presença de matéria estranha nas amostras de chá verde. Conforme o autor a maior parcela das amostras apresentou-se imprópria para consumo, em conformidade com a legislação vigente, em relação ao teor de chumbo encontrado nas folhas, no entanto as concentrações de arsênio e cádmio estejam dentro dos padrões exigidos. Quanto as infusões de $C$. sinensis essas não resultaram em concentrações de chumbo, arsênio e cádmio, maiores que as prescritas para a água potável, porém a ingestão constante contribui para o consumo diário desses contaminantes, o que pode, a longo prazo induzir a patologias associadas a cada um, uma vez que esses matais se acumulam no organismo e o chá verde não é a única fonte desses contaminantes.

Saigg (2009) destaca que: A grande preocupação de pesquisadores e da indústria farmacêutica é encontrar substâncias que apresentem boa eficácia no combate das doenças atuais e baixa toxicidade. Pelos estudos já realizados, conclui-se que as catequinas presentes em chás, principalmente no chá verde, têm demonstrado atividade quimioprotetora. Acredita-se também que os flavonoides fazem deles alimentos funcionais. No entanto, os estudos sobre o potencial efeito benéfico dos flavonoides para a saúde humana são ainda inconsistentes, apesar de intensa investigação sobre este assunto.

Urzedo (2020) salienta que: Atuais estudos científicos que a C. sinensis é uma planta importante para a saúde, assim as pesquisas com esse tipo de chá revelaram seu efeito sobre estados patológicos. Todavia, é sempre importante e válida a busca de novos resultados que ajudem a esclarecer os benefícios do chá verde, como também seus efeitos, uma vez que grande parte da população consome este chá por suas propriedades benéficas ao ser humano.

Beltran et al. (2014) destaca que o chá verde se apresenta efetivo em diversos estudos em diferentes situações, no entanto ainda precisa ser amplamente estudado, uma vez que os meios de ação se modificam, e a dosagem adequada ao consumo diário ainda não possui uma recomendação exata. Para Senger, Schwanke e Gottlieb (2010) complementam ser importante destacar a demanda por mais estudos experimentais e clínicos de modo aprofundado que envolvem além dos mecanismos de ação dos compostos bioativos do chá verde, biodisponibilidade, mais ainda a análise do background genético 
(polimorfismos) e estilo de vida dos indivíduos que ingerem esse alimento, para que se elucide a sua real ação efetiva no organismo.

Saigg (2009) também ressalta ser necessária a realização de mais pesquisas quanto a interação dos componentes do chá verde com os alimentos, a sua biodisponibilidade e os fatores antinutricionais, bem como as possíveis reações adversas a fim de não acarretem complicações para pacientes pertencentes a grupos específicos como crianças, idosos e grávidas.

\section{Considerações Finais}

O alimento funcional tem sido relatado como um fator importante nos processos fisiológicos. O consumo do chá verde tem se mostrado de grande utilidade em processos patológicos, doenças crônicas não transmissíveis, ao passo que é usado com um alimento funcional. Os efeitos do consumo contínuo da $C$. sinensis para saúde vem sendo eficaz no que condiz, uma ingestão balanceada e individualizada. Os efeitos pelo qual o chá verde apresenta as diversas funcionalidades tratadas no presente estudo é que o mesmo é rico em compostos fenólicos os quais são antioxidantes que combatem as espécies reativas e que podem ter diversas atividades no organismo. Por meio desse estudo constatou-se que o chá verde possui funcionalidades antioxidantes, ação contra doenças crônicas; ação anti sobrepeso e obesidade; ação antibactericida e antiviral. No entanto, fazse essencial o desenvolvimento de mais estudos que visem comprovar os efeitos do consumo do chá verde em seres humanos.

\section{Referências}

Anderson, R. A., \& Polansky, M. M. (2002). Tea enhances insulin activity. Journal of agricultural and food chemistry, 50(24), 7182-7186. https://www.researchgate.net/publication/11038207_Tea_Enhances_Insulin_Activity.

Annelli, C. L., Pereira T. B., De Oliveira L. C. N., Bernardo D. N. D. \& Grigoleto B. M. (2016). Fat, Reduction of Body. Efeitos funcionais das catequinas do chá verde na redução de gordura corporal. Revista Odontológica de Araçatuba, 37(2), 46-51. https://apcdaracatuba.com.br/revista/2016/12/7.

Appelt, A. V. (2019). Estudo de processos de infusão e transferência de resina em materiais compósitos. Monografia (Bacharel em Engenharia de Produção). Universidade do sul de Santa Catarina. Palhoça. https://repositorio.animaeducacao.com.br/handle/anima/4247.

Beltran, C. C., Silva, N. A., Grignoli, L. C. E., Simionato, M. I. V. \& Grignoli, C. R. E. (2014). Os benefícios do chá verde no metabolismo dão gordura corporal. Revista Científica da FHO|UNIARARAS, 2(1), 1-9. http://www.uniararas.br/revistacientifica.

Blanco, A. R. Os benefícios do chá verde (Camellia sinensis). (2020). http://jardimdeflores.com.br/sinergia/S08chaverde.htm.

Block, G., Patterson, B., \& Subar, A. (1992). Fruit, vegetables, and cancer prevention: a review of the epidemiological evidence. Nutrition and cancer, 18(1), $1-29$.

Brasil. Ministério da Saúde. Agência Nacional de Vigilância Sanitária. (2005). Resolução RDC no 266, de 22 de setembro de 2005. Regulamento técnico para gelados comestíveis e preparados para gelados comestíveis. Diário Oficial da República Federativa do Brasil, Poder Executivo, Brasília, DF. https://bvsms.saude.gov.br/bvs/saudelegis/anvisa/2005/res0266_22_09_2005.html.

Brasil. Ministério da Saúde. Agência Nacional de Vigilância Sanitária. Resolução no ${ }^{\circ}$, de 30 de abril de 1999 . Regulamento Técnico que estabelece as diretrizes básicas para análise e comprovação de propriedades funcionais e ou de saúde alegadas em rotulagem de alimentos. Diário Oficial da União, Brasília. https://www.in.gov.br/materia/-/asset_publisher/Kujrw0TZC2Mb/content/id/34379910/do1-2018-07-27-resolucao-da-diretoria-colegiada-rdc-n-241de-26-de-julho-de-2018-34379900.

Cabrera, C., Gimenez, R. \& Lopez, M. C. (2003). Determination of tea components with antioxidant activity. Journal Agricultural Food Chemistry, 51(15), 4427-4435 https://pubmed.ncbi.nlm.nih.gov/12848521/.

Cardoso, G. A. Efeito do consumo de chá verde aliado ou não ao treinamento de força sobre a composição corporal e taxa metabólica de repouso em mulheres com sobrepeso ou obesas. (2011). Dissertação (Mestre em Ciências e Tecnologias de Alimentos) - Departamento de Escola Superior de Agricultura "Luiz de Queiroz", Universidade de São Paulo, Piracicaba. https://www.teses.usp.br/teses/disponiveis/11/11141/tde-18102011-155801/pt-br.php.

Carmo, J. L. Silvestre, M. D. (2012). Design emocional aplicado no desenvolvimento de embalagens para chá. Monografia (Bacharel em Design). Universidade Tecnológica Federal do Paraná. Curitiba. https://repositorio.utfpr.edu.br/jspui/handle/1/7755.

Cooper R, Morré J. \& Morré D. M. Medicinal benefits of green tea: part I. (2005). Review Of Noncancer Health Benefits. The Journal of Alternative and Complementary Medicine. São Paulo, 521 528. https://www.docsity.com/pt/handbook-of-antioxidants/4862687/.

Duarte, J. L. G., Pretto, A. D. B., Nörnberg, F. R. \& Conter, L. F. (2014). A relação entre o consumo de chá verde e a obesidade: Revisão. RBONE-Revista Brasileira de Obesidade, Nutrição e Emagrecimento, 8(43), 31- 39. https://dialnet.unirioja.es/descarga/articulo/4837963.pdf

Duarte, M. R., Menarim, D. O. (2006). Morfodiagnose da anatomia foliar e caulinar de Camellia sinensis (L.) Kuntze, Theaceae. Revista Brasileira de Farmacognosia, 16(4), 545-551. https://www.scielo.br/j/rbfar/a/XrGkBXwvxHzDPKPSxhqYgpf/?lang=pt. 
Duboc, P. P. (2015). Determinação de arsênio, cádmio e chumbo nas folhas e na Infusão de chás de camellia sinensis comercializados no Rio de Janeiro, Brasil. Monografia (Especialista em Vigilância Sanitária). Instituto Nacional de Controle de Qualidade em Saúde da Fundação Oswaldo Cruz. Rio de Janeiro. https://www.arca.fiocruz.br/bitstream/icict/14733/2/Especializacao_residencia_Priscila_Duboc.pdf..

Esteves, E. (2021). Como o chá e o cafezinho movimentam bilhões no brasil e no mundo. https://www.eql.com.br/financas/2021/06/como o-cha-eo-cafezinho-movimentam-bilhoes-no-brasil-e-no-mundo/.

Faller, A. L. K., Fialho, E. (2009). Disponibilidade de polifenóis em frutas e hortaliças consumidas no Brasil. Artigos Originais. Rev Saúde Pública. 43(2), 211-8. https://www.scielo.br/j/rsp/a/3WZmsb4q6n9ZQJq4vQ4XpdB/?lang=pt\&format=pdf.

Faria, F., Santos, R. S. \&Viana, L. M. (2006). Consumo de Camellia sinensis em população de origem oriental e incidência de doenças crônicas. Revista de Nutrição, Campinas, 19(2), 275-279, mar./abr. https://www.scielo.br/j/rn/a/5ZKvxnMYkptnfqZP4Z9GYyf/abstract/?lang=pt.

Faria, J. B. L. (2015) Efeitos do chá verde (Camellia sinensis), do cacau e de um doador de óxido nítrico na nefropatia e retinopatia diabética: papel da redução do estresse oxidativo e da inflamação e do aumento do óxido nítrico. Faculdade de Ciências Médicas (FCM). Universidade Estadual de Campinas (UNICAMP). Campinas, SP, Brasil. https://bv.fapesp.br/pt/auxilios/5457/efeitos-do-cha-verde-camellia-sinensis-do-cacau-e-de-um-doador-de-oxido-nitricona-nefropatia-e-reti/.

Firmino, L. A. (2011). Avaliação da qualidade de diferentes marcas de chá verde (Camellia sinensis) comercializadas em Salvador-Bahia. Dissertação de Mestrado. Universidade Federal da Bahia. Faculdade de Farmácia. https://repositorio.ufba.br/ri/handle/ri/8804.

Firmino, L. A., Miranda, M. P. S. (2015). Polifenóis totais e flavonoides em amostras de chá verde (Camellia sinensis L.) de diferentes marcas comercializadas na cidade de Salvador-BA. Revista Brasileira de Plantas Medicinais, 17, 436-443 .https://www.scielo.br/j/rbpm/a/H5H4rszN X3Pp9DFxXJdfN6z/?lang=pt\&format=pdf.

Freitas, H. C. P., (2007). Navarro, F. O chá verde induz o emagrecimento e auxilia no tratamento da obesidade e suas comorbidades. Revista Brasileira de Obesidade, Nutrição e Emagrecimento. v.1, n.2, p.16-23. https://dialnet.unirioja.es/descarga/articulo/4837889.pdf.

Gondoin, A., Grussu, D., Stewart, D. \& Mcdougal, G. J. (2010). White and green tea polyphenols inhibit pancreatic lipase in vitro. Food Research International, vol. 43, n. 5, p.1537-1544, jun. https://www.sciencedirect.com/science/article/abs/pii/S096399691000147X?via\%3Dihub.

Hamilton-Miller, J. M. (1995). Antimicrobial properties of tea (Camellia sinensis L.). Antimicrobial agents and chemotherapy, 39(11), $2375-2377$. https://www.ncbi.nlm.nih.gov/pmc/articles/PMC162950/.

Hara, Y. (1995). Chemical composition of tea. Food Reviews International, 11, 435- 456. https://www.tandfonline.com/doi/abs/10.1080/87559129509541053.

Hilal, Y., Engelhardt, U. (2007). Characterisation of white tea - Comparison to green and black tea. Journal für Verbraucherschutz und Lebensmittelsicherheit, 2(4), 414-421. https://www.tu-braunschweig.de/fileadmin/Redaktionsgruppen/Institute_Fakultaet_2/ILC/PDFs/w_t.pdf.

Hughes, L., Arts, L. C. W, Ambergen, T., Brants, H. A. M., Dagnelie, P. C., Goldbohm, R. A., Brandt, P. A. V. D. \& Weijenberg, M. P. (2008). Higher dietary flavone, flavonol, and catechin intakes are associated with less of an increase in BMI over time in women: a longitudinal analysis from the Netherlands Cohort Study. The American journal of clinical nutrition, 88(5), 1341-1352. https://pubmed.ncbi.nlm.nih.gov/18996871/.

Institute For Sustainable Development - IISD. (2019). Relatório de mercado global: chá. https://www.iisd.org/publications/global-market report-tea.

International Institute For Sustainable Development - IISD. (2019). https://www.iisd.org/.

Kawai, K., Tsuno, N. H., Kitayama, J., Okaji., Yazawa, K., Asakage, M, Hori, N., Watanabe, T., Takahashi, K. \& Nagawa, H. (2003). Epigallocatechin gallate, the main component of tea polyphenol, binds to CD4 and interferes with gp120 binding. Journal of Allergy and Clinical Immunology, 112(5), 951-957. https://europepmc.org/article/med/14610487.

Komorita, Y., Hiroki Fujii, H., Ohkuma, T., Ide, H., Jodai-Kitamura, T., Yoshinari, M., Oku, Y., Higashi, T., Nakamura, U. \& Kitazono, T. (2020). Additive effects of green tea and coffee on all-cause mortality in patients with type 2 diabetes mellitus: the Fukuoka Diabetes Registry. BMJ Open Diabetes Research and Care, 8(1), e001252. http://dx.doi.org/10.1136/bmjdrc-2020-001252

Lamarão, R.C., Fialho, E. (2009). Aspectos funcionais das catequinas do chá verde no metabolismo celular e sua relação com a redução da gordura corporal. Revista de Nutrição, 22, 257-269. https://doi.org/10.1590/S1415-52732009000200008

Lima, J. D., Mazzafera, P., Moraes, W. S. \& Silva, R. B. (2009). Chá: aspectos relacionados à qualidade e perspectivas. Ciência Rural, 39, 1258-1266. https://doi.org/10.1590/S0103-84782009005000026

LOPES, D. (2015). Atualização em chá verde - Camellia sinensis.

Manenti, A. V. (2010). Plantas medicinais utilizadas no tratamento da obesidade: uma revisão. Monografia (Bacharel em Nutrição). Universidade do Extremo Sul Catarinense. Criciúma. http://repositorio.unesc.net/handle/1/127.

Manfredini, V., Martins, V. D. \& Benfato, M. S. (2004). Chá verde: benefícios para a saúde humana. Infarma-Ciências Farmacêuticas, 16(9/10), 68-70. http://www.revistas.cff.org.br/infarma/article/view/307.

Miranda, A. S. (2013). A utilização do chá verde para o emagrecimento: uma breve revisão. Monografia (Bacharel em Farmácia). Faculdade de Educação e Meio Ambiente - FAEMA. Ariquemes. http://repositorio.faema.edu.br/handle/123456789/327.

Nagão, T., Komine, Y., Soga, S., Meguro, S., Hase, T., Tanaka, Y. \& Tokimitsu, I. (2005). Ingestion of a tea rich in catechins leads to a reduction in body fat and malondialdehyde-modified LDL in men. The American journal of clinical nutrition, 81(1), 122-129. Disponível em: https://doi.org/10.1093/ajcn/81.1.122 
Nishiyama, M. F., Costa, M. A. F., Costa, A. M., Souza, C. G. M., Bôer, C. G., Bracht, C. K. \& Peralta, R. M. (2010). Chá verde brasileiro (Camellia sinensis var assamica): efeitos do tempo de infusão, acondicionamento da erva e forma de preparo sobre a eficiência de extração dos bioativos e sobre a estabilidade da bebida. Food Science and Technology, 30, 191-196. https://www.scielo.br/j/cta/a/W4TCb8zGSsP6CwSYkv454Sy/?lang=pt.

Oliveira, M. S. (2016). Chás e plantas medicinais: uma proposta experimental no ensino de química. Monografia (Licenciatura em Química). Universidade Federal do Pampa. Bagé. https://dspace.unipampa.edu.br/bitstream/riu/2746/1/TCC\%20Marcele\%20Oliveira 202016.pdf.

Ota, N., Soga, S., Shimotoyodome, A., Haramizu, S., Inaba, M., Murase, T., et al. (2005). Effects of combination of regular exercise and tea catechins intake on energy expenditure in humans. Journal of Health Science, 51(2), 233-236. https://www.jstage.jst.go.jp/article/jhs/51/2/51_2_233/_article.

Palermo, C. M., Hernando, J. I. M., Dertinger, S. D., Kende, A. S. \& Gasiewicz, T. A. (2003). Identification of potential aryl hydrocarbon receptor antagonists in green tea. Chemical research in toxicology, 16(7), 865-872. https://pubmed.ncbi.nlm.nih.gov/12870889/.

Pazinato, M. S., Braibante, H. T. S., Braibante, M. E. F., Trevisan, M. C. \& Silva, G. S. (2012). Uma abordagem diferenciada para o ensino de funções orgânicas através da temática medicamentos. Química Nova na Escola, 34(1), 21-25. http://qnesc.sbq.org.br/online/qnesc34_1/05-ea-43-11.pdf.

Petrin, N. Camellia sinensis. (2010). https://www.beneficiosdasplantas.com.br/camellia-sinensis-beneficios-e propriedades-dessa-planta-e-seu-cha/.

Reto, M., Figueira, E., Filipe, H.M., \& Almeida, C.M.M. (2008). Teor de fluoretos em infusões de chá verde (Camellia sinensis). Química Nova, 31, 317-320. https://doi.org/10.1590/S0100-40422008000200024

Rietveld, A., Wiseman, S. (2003). Antioxidant effects of tea: evidence from human clinical trials. The Journal of nutrition, 133(10), 3285S-3292S. https://pubmed.ncbi.nlm.nih.gov/14519827/.

Rijken, P.J., Wiseman, S.A., Weisgerber, U.M., Van Mierlo, C.A.J., Quinlan, P.T. \& Van De Put, F. (1996). Antioxidant and Other Properties of Green and Black Tea. In: Cadenas, E., Packer, L. Handbook of Antioxidants. 2nd ed. New York: Marcel Dekker. https://www.scielo.br/j/cta/a/W4TCb8zGSsP6CwSYkv454Sy/?lang=pt.

Sabu, M.C., Smitha, K. \& Kuttan, (2002). R. Anti-diabetic activity of green tea polyphenols and their role in reducing oxidative stress in experimental diabetes. Journal of ethnopharmacology, 83(1-2), 109-116.

Saffari, Y., Sadrzadeh, S. M. H. (2004). Green tea metabolite EGCG protects membranes against oxidative damage in vitro. Life sciences, 74(12), 1513-1518. https://core.ac.uk/reader/33558710.

Saigg, N. L. (2009). Efeitos da utilização do chá verde na saúde humana. Universitas: Ciências da Saúde, 7(1), 69-89. https://www.publicacoesacademicas.uniceub.br/cienciasaude/article/view/882.

Santos, A. C. P., Silva, T. C. (2017). Consumo de chá verde (camellia sinensis) e os seus benefícios sobre a densidade mineral óssea. Monografia (Bacharel em Nutrição). Universidade Federal De Goiás. Goiânia. https://repositorio.bc.ufg.br/bitstream/ri/13484/5/TCCG\%20-\%20Nutri\%C3\%A7\%C3\%A3o\%20\%20Ana\%20Carolina\%20Pereira\%20Santos\%20-\%202017.pdf.

Santos, J. M. (2012). Pesquisa de matérias estranhas em espécie vegetal, Pimpinella anisum L., para o preparo de "chá". Monografia (Especialização em Vigilância Sanitária) - Instituto Nacional de Controle de Qualidade em Saúde, Fundação Oswaldo Cruz. Rio de Janeiro. https://docplayer.com.br/22787950Presenca-de-materias-estranhas-em-erva-doce-pimpinella-anisum-1.html.

Santos, J. S., Escher, G. B., Carmo, M. V., Azevedo, L., Marques, M. B., Daguer, H., Molognoni, L., Genovese, M. I., Wen, M., Zhang, L., Oh, G. J., Shahidi, F. \& Granato, D. (2020). A new analytical concept based on chemistry and toxicology for herbal extracts analysis: From phenolic composition to bioactivity. Food Research International, 132, 109090. https://pubmed.ncbi.nlm.nih.gov/32331681/.

Santos, V. S. (2019). A química dos chás: o saber popular no ensino de química. Monografia (Licenciatura em Química). Universidade federal do recôncavo da Bahia. Amargosa. http://www.repositoriodi. Gital.ufrb.edu.br/bitstream/123456789/1550/1/tcc\%20vers\%c3\%83o\%20corr gida\%20pdf.pdf.

Schmitz, W., Saito, A. Y., Estevão, D. \& Saridakis, H. O. (2005). O chá verde e suas ações como quimioprotetor. Semina: Ciências biológicas e da saúde, 26(2), 119-130. http://dx.doi.org/10.5433/1679-0367.2005v26n2p119

SEBRAE. (2021). Produção de chás. https://www.sebrae.com.br/sites/portalsebrae/galeriavideo/producao-de chas,3109e71b5a208710vgnvem100000d701210arcrd.

Senger, A. E.V., Schwanke, C. H. A. \& Gottlieb, M. G. V. (2010). Chá verde (Camellia sinensis) e suas propriedades funcionais nas doenças crônicas não transmissíveis. Scientia Medica, 20(4), 292-300. https://revistaseletronicas.pucrs.br/ojs/index.php/scientiamedica/article/download/7051/5939/.

Senna, C. (2013). Enciclopédia do chá. In: Revista Casa e Jardim. http://revistacasaejardim.globo. Com/Revista/Common/0,EMI164823-18069,00ENCICLOPEDIA+DO+CHA.html.

Senna, C. Enciclopédia do chá. (2013). In: Revista Casa e Jardim. http://revistacasaejardim.globo. Com/Revista/Common/0, EMI164823-18069,00ENCICLOPEDIA+DO+CHA.html.

Urzedo, N. D. R. (2020) O chá verde e suas propriedades: uma breve revisão bibliográfica abrangendo os anos de 2000 a 2020. Monografia (Bacharel em Química Industrial). Universidade Federal de Uberlândia. Uberlândia. https://repositorio.ufu.br/handle/123456789/30879.

Vilela, M. C. L., \& Souza, M. F. C. (2015). Utilização da camellia sinensis no processo de emagrecimento. In II Congresso Internacional do Grupo Unis. Fundação de Ensino e Pesquisa do Sul de Minas. 
Research, Society and Development, v. 10, n. 14, e110101421638, 2021

(CC BY 4.0) | ISSN 2525-3409 | DOI: http://dx.doi.org/10.33448/rsd-v10i14.21638

Zhang, L., Santos, J. S., Cruz, T. M., Marques, M. B., Carmo, M. A. V., Azevedo, L., Wang, Y. \& Granato, D. (2019). Multivariate effects of Chinese keemun black tea grades (Camellia sinensis var. sinensis) on the phenolic composition, antioxidant, antihemolytic and cytotoxic/cytoprotection activities. Food Research International, 125, 108516. https://doi.org/10.1016/j.foodres.2019.108516 